\title{
ÁRVORES FREATÓFITAS: PROCESSO DE FITORREMEDIAÇÃO AOS RESÍDUOS INDUSTRIAIS
}

\author{
Fillipe Bani de Toledo da Silva ${ }^{1}$ \\ Thaís Luciana Faria ${ }^{2}$ \\ Ana Cabanas ${ }^{3}$ \\ Guilherme Silveira Simões ${ }^{4}$
}

Resumo: A preocupação da sociedade com as questões ambientais é um fator que impulsiona à reflexão sobre o tratamento dos solos que recebem resíduos provenientes de processos industriais. Por isso, esta investigação exploratória e bibliográfica, procura elucubrar acerca da propriedade de fitorremediação realizada por árvores freatófitas em solos contaminados por rejeitos industriais. Os resultados indicam que a fitorremediação consiste em uma técnica que utiliza as plantas para degradar, extrair, conter ou imobilizar contaminantes do solo e da água. Algumas regiões brasileiras têm utilizado o plantio de árvores freatófitas em terrenos contaminados. Os resultados eficazes dependem das características locais, da concentração e dos tipos de poluentes a serem removidos, além do uso final do meio contaminado. Conclui-se que os resíduos eliminados no solo provenientes da atividade industrial são considerados como fator preocupante à ciência e à sociedade. Portanto, novos experimentos sobre as técnicas de fitorremediação são indispensáveis para ampliar o conhecimento do potencial de descontaminação dos metais pesados do solo e as contribuições ao meio ambiente.

Palavras-chave: Resíduos industriais; Metais pesados; Árvores freatófitas; Fitorremediação.

\footnotetext{
1 Engenharia de Produção/Faculdade Anhanguera de São José, Brasil. E-mail: lipeebani@gmail.com.

2 Engenharia de Produção/ Faculdade Anhanguera de São José, Brasil. E-mail: thaislucianafaria@gmail.com.

${ }^{3}$ Faculdade Anhanguera de São José, Brasil. E-mail: anakabanass@gmail.com.

${ }^{4}$ Faculdade Anhanguera de São José, Brasil. E-mail: Guilherme.simoes@aedu.com.
} 